\title{
Attachment Styles as a Predictor of Relational-self Construal
}

\author{
Yüksel Eroğlu \\ Correspondence: Yüksel Eroğlu, Faculty of Education, Bayburt University, Bayburt, Turkey \\ Received: January 4, 2016 \\ doi:10.11114/jets.v4i4.1276 \\ Accepted: January 8, 2016 \\ Online Published: February 16, 2016 \\ URL: http://dx.doi.org/10.11114/jets.v4i4.1276
}

\begin{abstract}
The purpose of this study is to examine relationships between attachment styles and relational self-construal. The study was carried out with 376 students (223 male, 153 female) enrolled in different faculties of Bayburt University. The data was collected using the Relationship Scales Questionnaire and Relational-Interdependent Self-Construal Scale. In the study, the relationships between the attachment styles and the relational self-construal were analyzed via the Pearson correlation analysis. In order to analyze the predictive role of the attachment styles on the relational self-construal, the multiple regression analysis was used. Pearson correlation analysis indicated that the relational self-construal was positively related with the secure and preoccupied attachment styles, but negatively related with the dismissive and fearful attachment styles. According to the multiple regression analysis results, the dismissive, preoccupied and secure attachment styles accounted for $17 \%$ of the variance in the relational self-construal. Furthermore, the relational self-construal was predicted positively by the secure and the preoccupied attachment styles, but negatively by the dismissive attachment style.
\end{abstract}

Keywords: fearful, secure, dismissing, preoccupied, sense of self

\section{Introduction}

In the introduction section, firstly attachment styles and relational self-construal were explained and then the purpose of the study was discussed in detail.

\subsection{Attachment Styles}

The concept of attachment refers to the natural tendency towards establishing closeness and emotional attachment to important figures. Attachment styles resulting from relationships with fundamental figures in childhood period show themselves in the advancing periods of life, too, and called adult attachment styles. Individuals encode early experiences which they live with fundamental figures in childhood period as cognitive representations about themselves and others. These cognitive representations form the internal working models of the social world and affect individuals' perceptions, emotions and expectations in their interpersonal relationships (Gallitto \& Leth-Steensen, 2015). Moreover, it is reported that individuals' attachment styles have serious effects on not only their interpersonal relationships but also their professional lives (Doğan, 2009; Leiter, Day, \& Price, 2015).

It is expressed that adult attachment styles are characterized by two dimensions, namely anxiety and avoidance. The dimension of anxiety is characterized by an idividual's having a negative self-view, being oversensitive to rejection and having dificulty in trusting other individuals in interpersonal relationships. However, the dimension of avoidance reflects a negative view of others and the tendency towards independence, autonomy and social isolation (Pietromonaco $\&$ Feldman Barrett, 2000). The combination of these two dimensions forms the basis of secure and insecure attachment styles. The secure attchment style defined with low level of anxiety and avoidance reflects the harmony between independence and closeness. However, the insecure attachment style shows itself with difficulties in establishing close ties with important others in childhood and affects interpersonal relationships in adult life (Pickover, 2002). Moreover, the insecure attachment styles include individuals' living anxiety or avoidance to cope with problems, losses or abondonment which they encouner in interpersonal relationships. Anxious individuals strive to win other individuals' emotions. However, avoidant individuals tries to suppress relational needs (Hart, Nailing, Bizer \& Collins, 2015).

\subsection{Relational Self-Construal}

Self-construal is defined as the role which autonomy and relationships with other individuals play in the process of the structuring of self (Agrawal \& Maheswaran, 2005). Intercultural psychology has shown that individuals living in different cultures differ in self-construal (Kağıtçıbaşı, 2005). Indviduals living in individualistic society have a high 
opinion of autonomy, focus on their own internal values and abilities. These individuals behave in the direction of their own internal preferences and orientations and do not care other individuals' viewpoints. In this context, it can be stated that individuals living in individualistic societies develop independent self-construal. However, individuals living in collectivist societies structure their selves within the context of their social relationships and social attachments with other individuals. Individuals living in collectivist societies are motivated to establish social attachments, participate in social interactions and conform to social norms and develop an interdependent self-construal (Matsumoto \& Yoo, 2006).

Differences in self-construal provide important contributions in accounting for cultural differences. However, it is stated that there might be important differences between individuals living in the same culture in terms of self-construal as well. For example, some of the individuals having interdependent self-construal structure their selves in the context of social roles and groups to which they belong, another part of them in the context of their close relationships (relationships with mother, a good friend, spouse, etc.). Individuals' structuring their selves in the context of close relationships is called relational self-construal. In the relational self-construal, rather than sense of belonging, close relationships are important. In other words, selves of these individuals include their close relationships (King \& Ganotice, 2015).

\subsection{Purpose of the Study}

Close relationships play an important role in meeting individuals' fundamental sense of belonging needs (Segrin \& Taylor, 2007) and increase their well-being levels (Weger \& Emmett, 2009). For this reason, it is becoming important to investigate into variables contributing to individuals' establishing satisfying close relationships. One of these variables is relational self-construal. According to previous studies, the relational self-construal including the structuring of self in the context of close relationships motivates individuals to establish and maintain close relationships. In this context, researches demonstrated that relational self-construal is positively associated with the number of close relationships, satisfaction derived from close relationships, social support, empathy and paying more attention to other individuals' emotions and thoughts when making decisions (Cross, Morris, \& Gore, 2002; Cross, Bacon, \& Morris, 2000; Morry \& Kito, 2009) and negatively related with isolation, self-judgment, over-identification (Akın \& Eroğlu, 2013) and cyber bullying (Çetin, Eroğlu, Peker, Akbaba, \& Pepsoy, 2012).

Attachment styles play an important role in the regulation of emotions and behaviors in both childhood and adulthood (Shaver \& Mikulincer, 2002). For example, it was reported that children with the secure attachment style display emotionally and sociall competent behaviors, show higher self-controll skills, and respond with less anxiety and fear when faced problematic situations (Fraley \& Spieker, 2003). It is stated that the styles of attachment occurring as a resut of relationships established with the caregiver in the early periods of life lead to results which will continue lifelong in relation to interpersonal relationships and social functions in the adulthood (Erözkan, 2015; Zayas, Mischel, Shoda, \& Aber, 2011). In this direction, it was found that those people with the secure attachment style develop more satisfying and longer relationships than those who have insecure attachment styles. Moreover, insecure attachment was determined to be related with divergence and low functionality in both individual and interpersonal areas of life (Lee \& Koo, 2015). Based on these findings, it can be put forward that attachment styles are related with relational self-construal. For this reason, in this study, the predictive roles of secure, dismissive, preoccupied and fearful attachment styles on relational self-construal will be investigated.

\section{Method}

In this section, explanatory information was provided about the research model, participants, measurement tools, procedure and statistical analysis.

\subsection{The Research Model}

In this study, relationships between the attachment styles and the relational self-construal were analyzed based on descpritive relational model. The descriptive relational model aims to reveal the existence and strength of relationships between variables. Moreover, the study benefited from the cross-sectional design providing information about current states of participants.

\subsection{Participants}

In the study participants were 376 students, 223 male (59.31\%) and 153 female (40.69\%), enrolled in different faculties of Bayburt University. The mean age of the participants aged between 17 and 25 years old is $20.16 \pm 1.91 .113$ of the participants were the 1st year (30.05\%), 121 were the 2nd year (32.18\%), 86 were the 3rd year $(22.87 \%)$ and 56 were the 4th year (14.9\%) students. 65 (17.28\%) of the participants came from low SES families, 297 (78. 99\%) came from mid-SES families and $14(3.73 \%)$ came from high SES families. 


\subsection{Measurement Tools}

The Relationship Scales Questionnaire and Relational-Interdependent Self-Construal Scale were used in this study. The Relational-Interdependent Self-Construal Scale was preferred in the measurement of self-construal because it was considered that this scale would produce more valid and reliable results. The reason for this was that this scale focuses on individuals' close relationships with their friends and family members. However, other scales measuring self-construal are administered to larger groups such as ethnic origin.

\subsubsection{Relationship Scales Questionnaire}

In this study, with the aim of measuring the secure, fearful, preoccupied and dismissive attachment styles, the Relationship Scales Questionnaire (Griffin \& Bartholomew, 1994) was used. Adapted by Sümer and Güngör (1999) into Turkish, the Relationship Scales Questionnaire is composed of 17 items. Participants indicate how much they agree to items by using a 7-point Likert type grading varying between "1" (does not define me in any way) and "7" (exactly defines me). Sümer and Güngör (1999) stated that the Turkish version of the scale overlapped the original version of it. The reliability of the Turkish version of the scale was determined by calculating both the test-retest reliability and the Cronbach's alpha internal consistency coefficient. It was determined that the test-retest reliability of the Turkish version of the scale varied between .54 and .78 and the internal consistency coefficients varied between ise .27 and .61 (Sümer \& Güngör, 1999). In other studies made in Turkey (Gündüz, 2013; Ilhan, 2012; Odacı \& Çıkrıkç1, 2014; Şimşek, 2011), too, it was determined that the internal consistencies of the sub-scales were at low level. According to Griffin and Bartholomew (1994), the reason why the internal consistency coefficients of the sub-scales were found low was that the sub-scales included both the model belonging to self and the one belonging to others together. However, in this study, it was found that the internal consistency coefficients of the sub-scales varied between .41 and .64 .

\subsubsection{The Relational-Interdependent Self-Construal Scale}

The Relational-Interdependent Self-Construal Scale was developed by Cross et al. (2000) to measure relational-self construal and adapted by Akın, Eroğlu, Kayış and Satıcı (2010) into Turkish. The scale is composed of 11 items and has a structure with a single factor. Participants indicate how much they agree to the items by using a 7-point Likert type grading extending from "1" (I strongly disagree) to "7" (I strongly agree). Increasing scores obtained from the scale indicate increasing relational self-construal levels of individuals. While the Cronbach's alpha internal consistency coefficient of the scale was found as .85 in the Turkish adaptation study (Akın et al., 2010), it was determined as .81 in this study.

\subsection{Procedure}

Before carrying out the study, necessary permissions were taken from the heads of the departments. The scales were administered by the researcher in groups in the classrooms. Before the administration of the scales, the participants were given information about the purpose of the study. Moreover, the participants were told that the participation was based on voluntariness and they could leave whenever they liked. Besides this, the participants were told that the data to be obtained from the scales would be used only for this study.

\subsection{Statistical Analysis}

In this study, relationships between the secure, fearful, dismissive and preoccupied attachment styles and the relational self-construal were analyzed via using the Pearson Product Moments Correlation Coefficient. The predictive role of the attachment styles on the relational self-construal was analyzed via using the multiple regression analysis. In the multiple regression analysis, the stepwise method was used. Prior to the multiple regression analysis, it was investigated if the necessary assumptions (normality, multicollinearity, independence of residuals) were fulfilled. The analyses were made by using the PASW Statistics 18 program.

\section{Results}

In the section of findings, first of all, the descriptive statistics and the results obtained from the Pearson Correlation Analysis made between the attahment styles and relational self-construal were given. Moreover, in the second part, the results obtained from the multiple regression analysis related to the predictive effect of the attachment styles on the relational-self-construal were given.

\subsection{Descriptive Statistics and Pearson Correlation Analysis}

The mean, standard deviation, skewness and kurtosis values belonging to the variables included in the study and the results of the Pearson Product Moments Correlation Coefficient indicating the relationships between the secure, dismissive, preoccupied and fearful attachment styles and the relational self-construal were shown in Table 1 . 
Table 1. Descriptive statistics and Pearson correlation coefficients between attachment styles and relational-self construal

\begin{tabular}{|c|c|c|c|c|c|}
\hline Variables & 1 & 2 & 3 & 4 & 5 \\
\hline $\begin{array}{l}\text { 1. Relational self-construal } \\
\text { 2. Secure attachment style } \\
\text { 3. Dismissing attachment style } \\
\text { 4. Preoccupied attachment style } \\
\text { 5. Fearful attachment style } \\
\text { Mean } \\
\text { Standard Deviation } \\
\text { Skewness } \\
\text { Kurtosis }\end{array}$ & $\begin{array}{l}.28^{* *} \\
-.35^{* *} \\
.30^{* *} \\
-.16^{* *} \\
60.06 \\
10.06 \\
-.98 \\
.57\end{array}$ & $\begin{array}{l}-.41^{* *} \\
.27^{* *} \\
-.14^{* *} \\
21.53 \\
5.27 \\
.03 \\
-.17\end{array}$ & $\begin{array}{l}-.44^{* *} \\
.39^{* * *} \\
21.97 \\
7.20 \\
-.51 \\
-.38\end{array}$ & $\begin{array}{l}-.14^{* *} \\
15.93 \\
4.93 \\
.08 \\
-.42\end{array}$ & $\begin{array}{l}15.28 \\
4.40 \\
-.03 \\
-.15\end{array}$ \\
\hline
\end{tabular}

$* * \mathrm{p}<.01$

According to Table 1, the relational self-construal is positively related with the secure attachment style $\mathrm{r}_{(376)}=.28, \mathrm{p}<.01$, $95 \%$ CI $[.19, .37]$ and the preoccupied attachment style $\mathrm{r}_{(376)}=.30, \mathrm{p}<.01,95 \%$ CI $[.21, .39]$. On the other hand, there is a negative relationship between the relational self-construal and the dismissive attachment style $\mathrm{r}_{(376)}=-.35, \mathrm{p}<.01,95 \%$ CI $[-.44,-.26]$ and the fearful attachment style $\mathrm{r}_{(376)}=-.16, \mathrm{p}<.01,95 \%$ CI $[-.26,-.06]$. Besides this, the secure atachment style is negatively related with the dismissive $\mathrm{r}_{(376)}=-.41, \mathrm{p}<.01,95 \% \mathrm{CI}[-.49,-.32]$ and the fearful $\mathrm{r}_{(376)}=-.14, \mathrm{p}<.01$, $95 \% \mathrm{CI}[-.24,-.04]$ attachment styles, but it is positively related with the preoccupied attachment style $\mathrm{r}_{(376)}=.27, \mathrm{p}<.01$, $95 \% \mathrm{CI}[.17, .36]$. The dismisive attachment style is positively related with the fearful attachment style $\mathrm{r}_{(376)}=.39$, $\mathrm{p}<.01$, $95 \%$ CI $[.30, .47]$, but it is negatively related with the preoccupied attachment style $\mathrm{r}_{(376)}=-.44, \mathrm{p}<.01,95 \%$ CI $[-.52$, -.36]. Finally, it was found a negative relationship between the preoccupied attachment style and the fearful attachment style $\mathrm{r}_{(376)}=-.14, \mathrm{p}<.01,95 \%$ CI [-.24, -.04].

\subsection{Multiple Regression Analysis}

With the aim of examining the predictive role of the attachment styles on the the relational self-construal, the multiple regression analysis was made. Prior to the multiple regression analysis, it was examined if necessary assumptions were fulfilled. That the skewness and kurtosis values of the scores belonging to the secure, dismissive, fearful, preoccupied attachment styles and the relational self-construal varied between -1 and 1 (Tabachnick \& Fidell, 2013) indicates that the normality assumption was fulfilled. Moreover, with the aim of examining the multivariate normality assumption, the Mahalanobis distance values belonging to the variables included in the analysis were calculated and the Mahalonobis distance values $\left(\mathrm{D}^{2}\right)$ which were equal to $\mathrm{p}=.001$ or below were accepted as outliers and excluded from the anaysis. In other words, the Mahalonobis values which were above $\chi_{(4)}^{2}=18.465(\mathrm{p}=.001)$ were not included in the analysis. In this direction, in this study, 8 pieces of data were not taken into analysis. The multicollinearity problem was examined by using the VIF values and the VIF values were found below 10 (Tabachnick \& Fidell, 2013). Besides this, it was determined that all the tolerance values were below .20 (Tabachnick \& Fidell, 2013). This indicates that there was not a multi-collinearity problem. Moreover, the Durbin Watson coefficient was found as 1.97. That this coefficient varied between 1.5 and 2.5 (Field, 2009) indicates that there was not an autocorrelation; in other words, it indicates the independence of errors. On determining that the necessary assumptions were fulfilled, the stage of testing the regresssion model where the attachment styles were the predictive variables and the relational self-construal was the predicted variable started. During the multiple regression analysis, the stepwise method was used. The reason why the stepwise method was used was that it provided the opportunity to account for the model with a few number of variables (Tabachnick \& Fidell, 2013).

Table 2. Multiple regression analysis results for the prediction of relational-self construal by attachment styles

\begin{tabular}{lllll}
\hline Variables & B & Standard error of B & $\beta$ & $\mathrm{t}$ \\
\hline Step 1 & & & & $-7.20^{*}$ \\
Dismissing & -.49 & .07 & -.35 & $-5.05^{*}$ \\
Step 2 & & & & $3.39^{*}$ \\
Dismissing & -.38 & .08 & -.27 & -18 \\
Preoccupied & .37 & .11 & & $-3.83^{*}$ \\
Step 3 & & & -.22 & $3.10^{*}$ \\
Dismissing & -.30 & .08 & .17 & $2.82^{*}$ \\
Preoccupied & .34 & .11 & .15 & \\
Secure & .28 & .10 &
\end{tabular}

" $\mathrm{p}<.05$

As seen in Table 2, in the first stage of the multiple regression analysis, it was observed that the dismissive attachment style accounted for $12 \%$ of the relational self-construal $\left(R=.35, R^{2}=.12\right.$, adjusted $\left.R^{2}=.12, F(1,374)=51.80, p<.05\right)$. In the second stage of the multiple regression analysis, the preoccupied attachment style was taken into the regression 
model and made a contribution of $3 \%$ in accounting for the relational self-construal $\left(\mathrm{R}=.39, \mathrm{R}^{2}=.15, \Delta \mathrm{R}^{2}=.03\right.$, adjusted $\left.\mathrm{R}^{2}=.14, \mathrm{~F}(2,373)=32.36, \mathrm{p}<.05\right)$. In the third stage, the secure attachment style was also added to the regression model and made a contribution of $2 \%$ to the variance of the relational self-construal $\left(\mathrm{R}=.41, \mathrm{R}^{2}=.17, \Delta \mathrm{R}^{2}=.02\right.$, adjusted $\mathrm{R}^{2}=.16$, $\mathrm{F}(3,372)=24.62, \mathrm{p}<.05)$. These three variables together accounted for $17 \%$ of the variance in the relational self construal. Although the fearful attachment style was also added to the regression equation, it was observed that it did not make any contribution to the relational self-construal. The standardized beta coefficients indicated that the most important variable predicting the relational self-construal was the dismissive attachment style $(\beta=-.22, \mathrm{t}=-3.83, \mathrm{p}<.05)$ and this was followed in order by the preoccupied $(\beta=.17, \mathrm{t}=3.10, \mathrm{p}<.05)$ and the secure $(\beta=.15, \mathrm{t}=2.82, \mathrm{p}<.05)$ attachment styles.

\section{Discussion}

In this study, the predictive roles of the secure, dismissive, preoccupied and fearful attachment styles on the relational self-construal. According to the results of the study, the relational self-construal was predicted positively by the secure and preoccupied attachment styles and negatively by the dismissive attachment style. The research findings indicated that the relational self-construal was most strongly predicted by the dismissive attachment style and this was followed by the preoccupied and secure attachment styles.

The findings obtained from this study revealed that the most important predictor of the relational self-construal was the dismissive attachment style. Individuals with the dismissive attachment style avoid close relationships since they feel discontented especially in stressful situations. The dismissive attachment style has been characterized by low level of anxiety, high level of avoidance, positive self-view and negative view of others. These individuals avoid establishing close relationships and trusting other individuals. In addition to this, individuals with the dismissive attachment style evaluate themselves positively, but they continuously criticize people around them (Mikulincer, Shaver, \& Pereg, 2003). In the study carried out by Park, Crocker and Mickelson (2004), it was found that the individuals with the dismissive attachment style structured their self-esteem independently from reactions coming from other individuals. Moreover, in a study carried out by Lichtenstein, Christiansen, Elklit, Bilengerg, and Stoving (2014), it was determined that the individuals with the dismissive attachment style avoided trusting other individuals and exhibited narcissistic tendencies. When all these findings are evaluated together, the finding that as the dismissive attachment style increased, the relational self-construal decreased can be evaluated as an understandable finding.

In this study, it was determined that as the preoccupied attachment style increased, the relational self-construal increased. In the preoccupied attachment style, the individual is in need of establishing close relationships with other individuals (Permuy, Merino, \& Fernandez-Rey, 2010). These individuals developed negative self but positive others model. These individuals continuously desire to establish close relationships with other individuals, but fear of being rejected by them. That's why; they continuously try to meet the expectations of other individuals. Moreover, it was found that these individuals had low self-confidence (Howard \& Medway 2004). According to Mikulincer et al. (2003), since individuals with the preoccupied attachment style tend to perceive themselves as worthless, they try to increase their value by continuously receiving other individuals' approval. Besides this, in the study carried out by Heintzelman and Bacon (2015), it was determined that the individuals with high level of relational self-construal need more social support. Moreover, it was found that as the relational self-construal level increased, the effect of social support on life satisfaction increased (Heintzelman \& Bacon, 2015). When all these findings are evaluated as a whole, the finding that as the preoccupied attachment style increased, the relational self-construal increased, too, can be seen as an expected finding.

It was found that the secure attachment style predicted the relational self-construal positively in this study. In other words, as the secure attachment style increased, the relational self-construal increased, too. It was reported that the individuals with the secure attachment style have high emotional awareness levels and are successful at exhibiting appropriate social behaviors (Blalock, Franzese, Machell, \& Strauman, 2015). The individuals with the secure attachment style can easily establish social relationships (Gore \& Rogers, 2010), cope with stress by using active coping strategies (Leiter, Day, \& Price, 2015), behave equilibrating in their social relationships (Eng, Heimberg, Hart, Scheiner, \& Liebowitz, 2001) and express themselves comfortably in their social relationships (Mikulincer et al., 2003). Moreover, it was determined in the study made by Ilhan (2012) that the secure attachment style predicted loneliness negatively. People with whom they establish close relationships describe the individuals with the secure attachment style as friendly, honest and being open to novelties (Tambelli, Laghi, Odorisio, \& Notari, 2012). Acording to the findings obtained from this study, it can be stated that these characterstics which the individuals with the secure attachment style possess direct them to develop the relational self-construal.

In this study, no relationships were found between the fearful attachment style and the relational self-construal. The fearful attachment style was characterized by negative self and others model. The individuals with the fearful 
attachment style, too, like the ones with the preoccupied attachment style, desire to be accepted by other individuals and establish close relationships with them. However, these individuals fear of others' agonizing, rejecting and abandoning themselves. For this reason, they avoid developing intimacy with other individuals (Verdecias, Jean-Louis, Zizi, Casimir, \& Browne, 2009). That the individuals with the fearful attachment style both try to develop intimacy with other individuals and move away from them because of fearing of being rejected might have resulted in not finding a relationship between the fearful attachment style and the relational self-construal.

\section{Conclusion}

To my knowledge, this is the first study examining relationships between attachment styles and the relational self-construal. Attachment styles affect how individuals perceive and react to the world and cope with stressful events in interpersonal relationships. For this reason, in previous studies, many psychological constructs such as depression, anxiety, autism, eating disorders, problematic internet use, antisocial behaviors and burnout were taken as a function of individual differences in the attachment styles. The findings obtained from this study indicated that the attachment styles affected not only all these psychological constructs but also how self is structured. According to the findings obtained from this study, while the individuals with the secure and preoccupied attachment styles structure their selves within the context of their close relationships (relationships with mother, a good friend, spouse, etc.), the individuals with the dismissive attachment style refrain from this. No relationship was found between the fearful attachment style and the structuring of self within the context of close relationships. Making new studies to examine the role which close relationships play in the structuring of self in terms of attachment styles will help to reach more detailed findings. Moreover, making new studies examining the relationship between the relational self-construal and the attachment styles by including mediating and regulating variables will make it easy to understand the mechanism underlying this relationship better.

\section{Recommendations}

This study indicated that the attachment styles have an effect on relational self-construal. According to the findings obtained from this study, the individuals with the dismissive attachment style avoid establishing close relationships. In this direction, it is important to prepare intervention programs to help the individuals with the dismissive attachment style to establish social relationships. These individuals' participating in intervention programs increasing their social skills will help them to establish healthy social relationships. In this study, a positive relationship was found between the secure attachment style and the relational self-construal. In other studies, too, it was determined that the secure attachment style was related with personal and interpersonal positive functionality. It is stated that parents have a very important role in the development of the attachment styles (Mikulincer \&Shaver, 2007; Peker, 2015). In this context, it can be suggested that psychological counseling and guidance services should prepare behavioral programs with the aim of training parents to support their children's developing secure attachment style. Lastly, with the aim of strengthening the findings obtained from this study, it can be suggested to make new studies examining the relationship between the attachment styles and the relational self-construal by including different psychological constructs (personal self-esteem, relational self-esteem, parental and peer relationships, etc.).

\section{Limitations}

The findings obtained from this study should be interpreted by considering various limitations. Firstly, in this study, the cross-sectional design was used. For this reason, causal inferences cannot be made. Therefore, it can be suggested that new longitudinal and experimental studies should be made. Secondly, in this study, the measurment tools based on self-report were used. In this context, it can be suggested that new studies shuld be made based on behavioral observation and peer evaluation. Thirdly, this study was carried out with university students. For this reason, the findings obtained from this study are limited only to university students and cannot be generalized to other individuals (for example, adolescents). In this direction, it can be suggested that new studies should be made with new sample groups. Fourthly, in this study, the attachment styles were measured via the Relationship Scales Questionnaire. It can be suggested to make new studies by using different measurement tools measuring the attachment styles (for example, the Attachment to Parents and Friends Inventory, the Experiences in Close Relationships Inventory). Lastly, this study was carried out in Turkey where individuals have become open to the effect of individualistic Western cultures under the effect of globalization although they protect their ties with the traditional culture emphasizing harmony and closeness in relationships (Kağıtçıbaşı, 2005). For this reason, repeating this study in individualistic and collectivistic different cultures will strengthen its findings.

\section{References}

Agrawal, N., \& Maheswaran, D. (2005). Motivated reasoning in outcome bias effects. Journal of Consumer Research, $31,798-805$. 
Akın, A., \& Eroğlu, Y. (2013). Self-compassion and relational-interdependent self-construal. Studia Psychologica, 55(2), 111-121.

Akın, A., Eroğlu, Y., Kayış, A. R., \& Satııı S. A. (2010). The validity and reliability of the Turkish version of the Relational-Interdependent Self-Construal Scale. Procedia-Social and Behavioral Sciences, 5, 579-584.

Blalock, D. V., Franzese, A. T., Machell, K. A., \& Strauman, T. J. (2015). Attachment style and self-regulation: How our patterns in relationships reflect broader motivational styles. Personality and Individual Differences, 87, 90-98. http://dx.doi.org/10.1016/j.paid.2015.07.024

Cross, S. E., Bacon, P. L., \& Morris, M. L. (2000). The relational-interdependent self-construal and relationships. Journal of Personality and Social Psychology, 78(4), 791-808.

Cross, S. E., Morris, M. L., \& Gore, J. S. (2002). Thinking about oneself and others: The relational-interdependent self-construal and relationships. Journal of Personality and Social Psychology, 82(3), 399-418.

Çetin, B., Eroğlu, Y., Peker, A., Akbaba, S., \& Pepsoy, S. (2012). The investigation of relationship among relational-interdependent self-construal, cyberbullying, and psychological disharmony in adolescents: An investigation of structural equation modelling. Educational Sciences: Theory \& Practice, 12(2), 646-653.

Doğan, U. (2009). Rehber ögretmenlerin duygusal zeka ve bağlanma stillerinin bazı değişkenlere göre incelenmesi. X. Ulusal Psikolojik Danışma ve Rehberlik Kongresi’nde sözlü bildiri olarak sunulmuştur, Adana, Türkiye.

Eng, W., Heimberg, R. G., Hart, T. A., Schneier, F. R., \& Liebowitz, M. R. (2001). Attachment in individuals with social anxiety disorder: The relationship among adult attachment styles, social anxiety, and depression. Emotion, 1(4), 365-380.

Erözkan, A. (2015). The childhood trauma and late adolescent rejection sensivity. Anthropologist, 19(2), 413-422.

Field, A.P. (2009). Discovering statistics using SPSS: And sex, drugs and rock roll (3rd ed). Los Angeles: SAGE Publications.

Fraley, R. C., \& Spieker, S. J. (2003). Are infant attachment patterns continuously or categorically distributed? A taxometric analysis of strange situation behavior. Developmental Psychology, 39, 387-404.

Gallitto, E., \& Leth-Steensen, C. (2015). Autistic traits and adult attachment styles. Personality and Individual Differences, 79, 63-67. http://dx.doi.org/10.1016/j.paid.2015.01.032

Gore, J. S., \& Rogers, M. J. (2010). Why do I study? The moderating effect of attachment style on academic motivation. The Journal of Social Psychology, 150(5), 560-578. http://dx.doi.org/10.1080/00224540903365448

Griffin, D., \& Bartholomew, K. (1994). Models of the self and other: Fundamental dimensions underlying measures of adult attachment. Journal of Personality and Social Psychology, 67(3), 430-445.

Gündüz, B. (2013). The contributions of attachment styles, irrational beliefs and psychological symptoms to the prediction of cognitive flexibility. Educational Sciences: Theory \& Practice, 13(4), 2071-2085. http://dx.doi.org/10.12738/estp.2013.4.1702

Hart, J., Nailling, E., Bizer, G. Y., \& Collins, C. K. (2015). Attachment theory as a framework for explaining engagement with Facebook. Personality and Individual Differences, 77, 33-40. http://dx.doi.org/10.1016/j.paid.2014.12.016

Heintzelman, S. J., \& Bacon, P. L. (2015). Relational self-construal moderates the effect of social support on life satisfaction. Personality and Individual Differences, 73, 72-77. http://dx.doi.org/10.1016/j.paid.2014.09.021

Howard, M. S., \& Medway, F. J. (2004). Adolescents' attachment and coping with stress. Psychology in the Schools, 41(3), 391-402. http://dx.doi.org/10.1002/pits.10167

İlhan, T. (2012). Loneliness among university students: Predictive power of sex Roles and attachment Styles on loneliness. Educational Sciences: Theory \& Practice, 12(4), 2377-2396.

Kağıtçıbaşı, Ç. (2005). Autonomy and relatedness in cultural context. Journal of Cross-Cultural Psychology, 36(4), 403-422.

King, R. B., \& Ganotice, F. A. (2015). Does family obligation matter for students' motivation, engagement, and well-being?: It depends on your self-construal. Personality and Individual Differences, 86, 243-248. http://dx.doi.org/10.1016/j.paid.2015.06.027

Lee, J. S., \& Koo, H. J. (2015). The relationship between adult attachment and depression in Korean mothers during the first 2 years postpartum: A moderated mediation model of self-esteem and maternal efficacy. Personality and Individual Differences, 79, 50-56. http:// dx.doi.org/10.1016/j.paid.2015.01.021

Leiter, M. P., Day, A., \& Price, L. (2015). Attachment styles at work: Measurement, collegial relationships, and burnout. Burnout Research, 2(1), 25-35. http://dx.doi.org/10.1016/j.burn.2015.02.003

Lichtenstein, M. B., Christiansen, E., Elklit, A., Bilengerg, N., \& Stoving, R. K. (2014). Exercise addiction: a study of 
eating disorder symptoms, quality of life, personality traits and attachment styles. Psychiatry Research, 215(2), 410-416. http://dx.doi.org/ 10.1016/j.psychres.2013.11.010

Matsumoto, D., \& Yoo, S. H. (2006). Toward a new generation of cross-cultural research. Perspectives on Psychological Science, 1(3), 234-250. http://dx.doi.org/ 10.1111/j.1745-6916.2006.00014.x

Mikulincer, M., Shaver, P. R., \& Pereg, D. (2003). Attachment theory and affect regulation: The dynamics, development, and cognitive consequences of attachment-related strategies. Motivation and Emotion, 27(2), 77-102.

Mikulincer, M., \& Shaver, P. R. (2007). Attachment in adulthood: Structure, dynamics, and change. New York: Guilford Press.

Morry, M. M., \& Kito, M. (2009). Relational-interdependent self-construal as a predictor of relationship quality: The mediating roles of one's own behaviors and perceptions of the fulfillment of friendship functions. The Journal of Social Psychology, 149(3), 305-322. http://dx.doi.org/10.3200/SOCP.149.3.305-322

Odacı, H., \& Çıkrıkçı, Ö. (2014). Problematic internet use in terms of gender, attachment styles and subjective well-being in university students. Computers in Human Behavior, 32, 61-66. http://dx.doi.org/10.1016/j.chb.2013.11.019

Park, L. E., Crocker, J., \& Mickelson, K. D. (2004). Attachment styles and contingencies of self-worth. Personality and Social Psychology Bulletin, 30(10), 1243-1254.

Peker, A. (2015). Öz-Değer. In A. Akın \& U. Akın (Eds.), Psikolojide güncel kavramlar (pp.93-104). Ankara: Nobel Publishing Company.

Permuy, B., Merino, H., \& Fernandez-Rey, J. (2010). Adult attachment styles and cognitive vulnerability to depression in a sample of undergraduate students: the mediational roles of sociotropy and autonomy. International Journal of Psychology, 45(1), 21-27. http://dx.doi.org/10.1080/00207590903165059

Pickover, S. (2002). Breaking the cycle: A clinical example of disrupting an insecure attachment system. Journal of Mental Health Counselling, 24, 358-367.

Pietromonaco, P. R., \& Feldman, B. L. (2000). The internal working models concept: What do we really know about the self in relation to others? Review of General Psychology, 4, 155-157. http://dx.doi.org/10.1037111089-2680.4.2.155

Segrin, C., \& Taylor, M. (2007). Positive interpersonal relationships mediate the association between social skills and psychological well-being. Personality and Individual Differences, 43, 637-646. http://dx.doi.org/10.1016/j.paid.2007.01.017

Shaver, P. R., \& Mikulincer, M. (2002). Attachment-related psychodynamics. Attachment \& Human Development, 4, 133-161.

Sümer, N., \& Güngör, D. (1999). Psychometric evaluation of adult attachment measures on Turkish samples and a cross-cultural comparison. Turkish Journal of Psychology, 14(43), 107-109.

Şimşek, Ö. F. (2011). Structural relations of personal and collective self-esteem to subjective well-being: Attachment as moderator. Social Indicator Research, 110(1), 219-236. http://dx.doi.org/10.007/s11205-011-99-27-1

Tabachnick, B. G., \& Fidell, L. S. (2013). Using multivariate statistics. Boston: Pearson.

Tambelli, R., Laghi, F., Odorisio, F., \& Notari, V. (2012). Attachment relationships and internalizing and externalizing problems among Italian adolescents: age and gender differences. Children and Youth Services Review, 34, 1465-1471.

Verdecias, N. R., Jean-Louis, G., Zizi, F., Casimir, G. J., \& Browne, R. C. (2009). Attachment styles and sleep measures in a community-based sample of older adults. Sleep Medicine, 10(6), 664-667. http://dx.doi.org/10.1016/j.sleep.2008.05.011

Weger, H., \& Emmett, M. C. (2009). Romantic intent, relationship uncertainty, and relationship maintenance in young adults' cross-sex friendships. Journal of Social and Personal Relationships, 26, 964-988. http://dx.doi.org/10.1177/0265407509347937

Zayas, V., Mischel, W., Shoda, Y., \& Aber, J. L. (2011). Roots of adult attachment: Maternal caregiving at 18 months predicts adult attachment to peers and partners. Social Psychology and Personality Science, 2(3), 289-297. http://dx.doi.org/10.1177/1948550610389822

\section{(c) BY}

This work is licensed under a Creative Commons Attribution 3.0 License. 